\title{
Management of osteoporosis in the elderly
}

R. Rizzoli ${ }^{\mathrm{a}}$, O. Bruyere ${ }^{\mathrm{b}}$, J. B. Cannata-Andia ${ }^{\mathrm{c}}$, J.-P. Devogelaer ${ }^{d}$, G. Lyritis ${ }^{e}$, J. D. Ringe ${ }^{f}$, B. Vellas $^{g}$ and J.-Y. Reginster ${ }^{\mathrm{b}}$

aDivision of Bone Diseases, Department of Rehabilitation and Geriatrics,

Geneva University Hospitals and Faculty of Medicine, Geneva, Switzerland

${ }^{b}$ Department of Public Health, Epidemiology and Health Economics,

University of Liège, Belgium

${ }^{c}$ Bone and Mineral Research Unit, Instituto Reina Sofía de Investigación,

REDinREN Carlos III. Hospital Universitario Central Asturias. Oviedo, Spain

${ }^{d}$ Department of Rheumatology, Catholic University of Louvain, Brussels,

Belgium

${ }^{e}$ Department of Orthopaedics, University of Athens, Greece

${ }^{f}$ Medizin. Klinik 4 (Dept. Rheumatology/Osteology) and West German

Osteoporosis Center (WOC) at Klinikum Leverkusen, University of

Cologne, Germany

gInserm U 558, University of Toulouse, France

Address for correspondence: René Rizzoli, Division of Bone Diseases, WHO Collaborating Center

for Osteoporosis Prevention, Department of Rehabilitation and Geriatrics, Geneva University

Hospitals and Faculty of Medicine, Rue Micheli-du-Crest 24, 1211, Geneva 14, Switzerland.

Tel.: +41 22372 9950; Fax: +41 2238299 73; Rene.Rizzoli@unige.ch

Keywords: Bisphosphonate - Falls - Frailty - Hip fracture - Osteoporosis - Strontium ranelate -

Vitamin D supplementation

\section{ABSTRACT}

Background: 0steoporosis is predominantly a condition of the elderly, and the median age for hip fracture in women is approximately 83 years. Osteoporotic fracture risk is multifactorial, and often involves the balance between bone strength and propensity for falling.

Objective: To present an overview of the available evidence, located primarily by Medline searches up to April, 2009, for the different management strategies aimed at reducing the risk of falls and osteoporotic fractures in the elderly.

Results: Frailty is an independent predictor of falls, hip fractures, hospitalisation, disability and death in the elderly that is receiving increasing attention. Non-pharmacological strategies to reduce fall risk can prevent osteoporotic fractures. Exercise programmes, especially those involving high doses of exercise and incorporating balance training, have been shown to be effective. Many older people, especially the very elderly and those living in care institutions, have vitamin D inadequacy. In appropriate patients and given in sufficient doses, vitamin $D$ and calcium supplementation is effective in reducing both falls and osteoporotic fractures, including hip fractures. Specific anti-osteoporosis drugs are underused, even in those most at risk of osteoporotic fracture. The evidence base for the efficacy of most such drugs in the elderly is incomplete, particularly with regard to nonvertebral and hip fractures. The evidence base is perhaps most complete for the relatively recently introduced drug, strontium ranelate. Non-adherence to treatment is a substantial problem, and may be exacerbated by the requirements for safe oral administration of bisphosphonates.

Conclusion: Evidence-based strategies are available for reducing osteoporotic fracture risk in the elderly, and include exercise training, vitamin $D$ and calcium supplementation, and use of evidence-based anti-osteoporotic drugs. A positive and determined approach to optimising the use of such strategies could reduce the burden of osteoporotic fractures in this highrisk group. 


\section{Introduction}

Osteoporosis is predominantly a condition of the elderly, although the age profile varies for different fractures. Wrist and distal forearm fractures are common in younger postmenopausal women, while the incidence of vertebral and especially hip fractures increases steeply with age (Figure 1$)^{1}$. Hip fractures are generally regarded as the most serious manifestation of osteoporosis, associated with substantial morbidity and mortality ${ }^{2-4}$, and over $90 \%$ of hip fractures require surgical treatment ${ }^{5,6}$. The incidence of hip fracture increases exponentially with age in women between 60 and approximately 85 years $^{7-9}$, beyond which it increases more slowly ${ }^{10}$. Nonetheless, $60 \%$ of hip fractures in women occur after the age of 80 years ${ }^{11}$, and the median age for hip fractures in women is approximately 83 years ${ }^{12-14}$ and appears to be increasing at a rate of 1 year every 5 years $^{3}$. Patients with a first hip fracture are at markedly elevated risk of a second hip fracture; nonetheless, the interval between fractures generally seems sufficient for interventions aimed at reducing the risk of subsequent fractures to be effective $^{15,16}$.

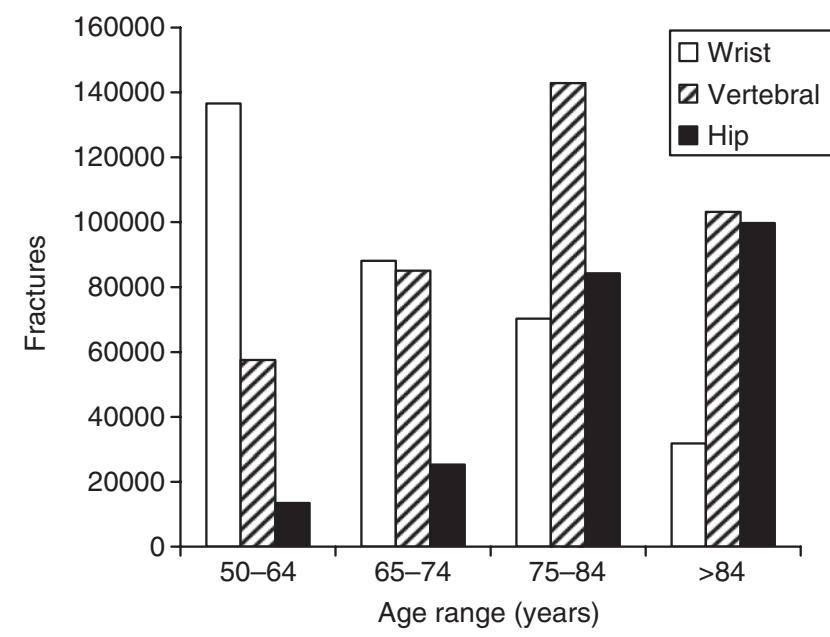

Figure 1. Estimated numbers of incidents of wrist, vertebral and hip fractures during the year 2005 in the USA, data from Burge et al. ${ }^{1}$

The risk of several types of osteoporotic fracture increases with age more rapidly than would be expected from age-related decrease in bone mineral density (BMD) $)^{17}$, and only approximately half of fragility fractures occur in women meeting current criteria for osteoporosis based on $\mathrm{BMD}^{18-20}$. Part of this discrepancy may be explained by the fact that many osteoporotic fractures are precipitated by falls ${ }^{21}$; some $98 \%$ of hip fractures are the result of falls ${ }^{22,23}$, although the proportion for vertebral fractures is lower ${ }^{7,24}$. The risk of many forms of osteoporotic fracture seems to be determined by the balance between bone strength and propensity for falling, leading to the suggestion that such fractures result from a combination of a 'bone and brain' disease $\mathrm{e}^{25}$.

In this article we aim to present an overview of the available evidence for the different management strategies that can contribute to reducing osteoporotic fractures in the elderly. The article stemmed from a meeting held in Paris, France in March, 2009 under the auspices of the European Society for Clinical and Economic Aspects of Osteoporosis and Osteoarthritis (ESCEO). Literature for consideration was obtained primarily by Medline searches spanning January, 1985 to April, 2009. In view of the large volume of published material, our review is not exhaustive, and we apologise to authors whose contributions have not been included. In selecting papers, we have tended to include the most recent at the expense of older references.

\section{Age and the evolving concept of frailty}

Neither chronological age nor BMD appear to capture fully the risk of osteoporotic fracture in elderly people or identify those who might benefit most from particular treatments or management. The concept of frailty has received increasing attention in recent years ${ }^{26}$. Various definitions of frailty have been proposed, but there is some consensus that frailty involves a decreased reserve or resistance to stressors, resulting in increased vulnerability to adverse outcomes including falls, disability, dependency and mortality ${ }^{27,28}$. Frailty can be distinguished from disability, dependency and comorbidity, and may confer specific health care needs ${ }^{28}$.

The most extensively studied operational definition of frailty was proposed by Fried and colleagues using data from the Cardiovascular Health Study (CHS), and is based on five characteristics: unintentional weight loss, muscle weakness, reduced energy and endurance, slowness of gait, and low physical activity level (Table 1$)^{27}$. People with none of these characteristics are considered to be robust, those with one or two as intermediate or pre-frail, and those with three or more are frail. In the CHS cohort, frailty was an independent predictor of falls, hospitalisation, disability and death, after adjustment for baseline factors. The independent predictive power of frailty has since been confirmed in other cohorts of women and men ${ }^{29-34}$, with prevalence varying between $4 \%$ and $25 \%$. In a recent study in community-dwelling individuals in 10 European countries $^{35}$, the overall prevalence of frailty was $4.1 \%$ among those aged 50 to 64 years, and $17.0 \%$ among those $\geq 65$ years. Both frailty and pre-frailty are more prevalent in women than in men $27,34,35$. 
Table 1. Elements of the Cardiovascular Health Study operational definition of frailty, the presence of three or more elements identifies frailty ${ }^{27}$

\begin{tabular}{ll}
\hline Element & \multicolumn{1}{c}{ Measure } \\
\hline Weight loss, sarcopenia & Unintentional loss of $>10$ lb in previous year \\
Muscular weakness & Grip strength in lowest quintile, adjusted for gender and body mass index \\
Exhaustion, poor endurance & Self-report of exhaustion \\
Slowness of gait & Time to walk 15 feet in lowest quintile, adjusted for gender and height \\
Low level of physical activity & Kilocalories expended in physical activity per week in lowest quintile, \\
& calculated using standardised algorithm and adjusted for gender \\
\hline
\end{tabular}

In 6742 women of mean age 76.7 years in the prospective Study of Osteoporotic Fractures ${ }^{33}$, frail women were at increased risk of falls, all non-spine fractures, hip fractures, and death compared with robust women, after adjustment for potential confounders including age and BMD. The associations between frailty and these adverse outcomes persisted among women $\geq 80$ years of age, and the authors concluded that these results support the notion that frailty is a distinctive and unique disorder.

There have been several attempts to modify the CHS operational definition of frailty. Inclusion of elements relating to cognitive or neurological status, such as cognitive impairment, may improve the predictive power of frailty ${ }^{36,37}$. On the other hand, some have argued that the CHS definition is impractical for use in clinical practice and have proposed simpler indices. An index based on data from the Study of Osteoporotic Fractures involves three components: weight loss (regardless of intent), reduced energy level, and inability to rise from a chair five times without using the $\operatorname{arms}^{38}$. This simpler index performed similarly to the CHS definition in predicting falls, fractures, disability and death, and may enable the identification of high-risk women in clinical practice. It is interesting to note that a recent study in Swedish twins aged $\geq 55$ years showed that simply asking the question 'Do you have impaired balance?' identified individuals at substantially increased risk of fracture, with approximately $40 \%$ of hip fractures attributable to self-reported impaired balance ${ }^{39}$.

Fried and colleagues ${ }^{27}$ envisaged a physiologically based 'cycle of frailty' involving, among others, chronic undernutrition, sarcopenia and reduced total energy expenditure that could lead to a potentially downward spiral. In addition to the obvious link between inadequate nutrition and weight loss, undernutrition certainly seems important in osteoporosis. Malnutrition is common in men and women aged $\geq 70$ years hospitalised for hip fracture ${ }^{40}$, and low scores $(<27$ points $)$ on the Mini-Nutritional Assessment are associated with a two-fold increase in the risk of osteoporosis ${ }^{41}$. There is also considerable interest in the underlying pathophysiological processes that may be involved in the development of frailty ${ }^{42}$. Oxidative stress ${ }^{43}$, dysregulated inflammatory processes ${ }^{44-46}$ and low serum concentration of 25-hydroxyvitamin D $[25(\mathrm{OH}) \mathrm{D}]^{47}$, have all been associated with incident and/or prevalent frailty and offer promising avenues for research. The recent development of a frail mouse model showing inflammation and strength decline consistent with human frailty ${ }^{48}$ should facilitate progress in understanding the biological basis of frailty.

A key difference between frailty and chronological age is that frailty is to some extent reversible. In a study of community-living individuals aged $\geq 70$ years, the proportion of individuals classed as frail increased with time, while the proportions of robust and pre-frail individuals decreased ${ }^{49}$. Importantly, however, there were a substantial number of transitions in the reverse direction. In each assessment period, up to $16.5 \%$ of pre-frail individuals changed classification to robust, and up to $23 \%$ of frail individuals made the transition to pre-frail, leading the authors to conclude that there is ample opportunity for prevention and remediation of frailty.

\section{Conclusions}

Frailty independently predicts risk of falls, hip fractures and mortality. As a concept, frailty highlights the multifactorial nature of osteoporotic fracture risk and provides a description of biological rather than chronological aging. In future, frailty may be useful to characterise participants in clinical trials, and the prevention or reversal of frailty could itself become a therapeutic target. Simple indices of frailty could be used to assess fracture risk in clinical practice.

\section{Non-pharmacological strategies to prevent falls in the elderly}

Falls and fall-related injuries are common in elderly people $^{50}$. It is estimated that $30 \%$ to $40 \%$ of generally 
Table 2. Risk factors for falls in the elderly, derived from 16 published studies (modified from reference ${ }^{53}$ )

\begin{tabular}{clc}
\hline Rank & \multicolumn{1}{c}{ Risk factor } & $\begin{array}{c}\text { Mean odds ratio or } \\
\text { relative risk ratio }\end{array}$ \\
\hline 1 & Muscle weakness & 4.4 \\
2 & History of falls & 3.0 \\
3 & Gait deficit & 2.9 \\
4 & Balance deficit & 2.9 \\
5 & Use of an assistive device & 2.6 \\
6 & Visual deficit & 2.5 \\
7 & Arthritis & 2.4 \\
8 & Impaired activities & 2.3 \\
& of daily living & 2.2 \\
9 & Depression & 1.8 \\
10 & Cognitive impairment & 1.7 \\
11 & Age $>80$ years & \\
\hline
\end{tabular}

${ }^{a}$ Odds ratio for retrospective studies, relative risk ratio for prospective studies

healthy, community-living persons aged $\geq 65$ years experience a fall in any given year, and the rates are higher for those resident in nursing homes and persons aged $\geq 75$ years $^{51-54}$. Over 15,000 people aged $\geq 65$ years are thought to have died from fall injuries in the USA during $2005^{55}$. Falls often lead to a loss of independence or admission to an institution ${ }^{56}$; approximately $50 \%$ of fall injuries sustained at home and requiring hospital treatment resulted in discharge into a nursing home ${ }^{57}$. A study in Finland found that the incidence of fall-related injuries increased by $284 \%$ between 1970 and 1995, and the trend was greatest in those aged $\geq 80$ years $^{58}$. The increase was more than could be explained by demographic changes, and may have been related to increased medication use and more active lifestyles among the elderly.

The incidence of falls among women increases sharply with age ${ }^{59-61}$, and most of the costs associated with falls are attributable to falls in those aged $\geq 75$ years ${ }^{62}$. In a survey of common risk factors for falls, the most powerful risk factor was muscle weakness, followed by a history of falls and gait deficit (Table 2$)^{53}$. It is notable that muscle weakness and gait deficit are two of the five elements assessed in the CHS definition of frailty ${ }^{27}$. Some medications may increase fall risk, including psychotropic drugs such as benzodiazepines, and cardiovascular drugs such as antiarrhythmics, digoxin and diuretics $^{63-65}$. Environmental factors such as poor lighting, loose or frayed carpets, and trailing electrical cables may also increase the risk of falling ${ }^{53,66}$.

Given the diversity of factors that may affect fall risk, it is not surprising that a wide range of interventional strategies to prevent falls has been explored. Gait training, exercise programmes, advice on use of assistive devices, review of existing medication, modification of environmental hazards and the wearing of hip protectors have all been evaluated individually or as components of a multifactorial interventional strategy ${ }^{50,53}$. However, as is commonly the case with non-pharmacological treatments, the studies are often small with varying methodology and criteria for selection of participants, and results have been inconsistent.

One recent meta-analysis of 19 studies of multifactorial assessment and intervention programmes found no significant benefit on the number of fallers or for fall-related injuries ${ }^{67}$. However, two Cochrane systematic reviews concluded that multifactorial programmes, and exercise programmes aimed at increasing muscle strength and improving balance, could significantly reduce the rate and risk of falls ${ }^{68,69}$. Differences in inclusion criteria among studies could partly explain the differences in the results of meta-analysis. The Cochrane reviews also showed that home safety interventions were effective in those at higher risk of falling and those with severe visual impairment.

An interdisciplinary assessment and referral programme was effective in reducing the risk of falling in community-dwelling individuals aged $\geq 65$ years in the United Kingdom ${ }^{70}$. Interestingly, a subsequent study in the Netherlands, based on the same intervention programme but integrated into routine health care, was not effective ${ }^{71}$, emphasising the potential difficulties of implementing such programmes in clinical practice as opposed to a research setting.

Different types of fall-prevention interventions were compared in a recent randomised trial ${ }^{72}$. A total of 150 participants, mean age 76.8 years, who had sustained recent falls were assigned to one of three interventions for a 4-month period: education (visits and pamphlets giving information on exercise, use of walking aids, and home environmental improvements); home safety assessment and modification (safety assessments and up to 14 inexpensive home modifications carried out); or exercise training (individualised programme, including trunk and leg strengthening and balance training). Quality-of-life and functional assessments supported the superiority of exercise training over the other interventions; however, it should be acknowledged that the number of falls and participants falling were not assessed in this study.

A recent review and meta-analysis sought not only to establish whether exercise training programmes were effective in preventing falls in older people, but also to determine the most effective components of the programmes ${ }^{73}$. The analysis included 44 studies involving 9603 participants and showed that patients who undertook exercise programmes had lower fall rates than those who did not (rate ratio $0.83, p<0.001$ ). 
The largest reductions were found in programmes with a high dose of exercise ( $>50 \mathrm{~h}$ over the study period) and those which involved highly challenging balance training (e.g. exercises conducted while standing in which people aimed to stand with their feet close together or on one leg, minimised the use of their hands to assist, and practiced controlled movements of their centre of mass). Exercise programmes that did not include walking reduced fall rates more than those that involved walking. Studies with all three desirable characteristics (high dose of exercise, balance training, no walking) gave an adjusted rate ratio of 0.58 (95\% CI 0.48-0.69), indicating a substantial reduction in fall risk. The negative influence of walking on fall rate may be due to time spent walking taking the place of balance training, which appears to be the most effective form of exercise. However, walking programmes have demonstrated other health benefits, including preventing bone loss in postmenopausal women ${ }^{74-76}$ and improving risk factors for cardiovascular disease . $^{77}$.

The importance of balance training was highlighted in a recent study in which tai chi training, three times per week for 6 months, was compared with a stretching control group in community-dwelling, physically inactive people of mean age 77.5 years ${ }^{78}$. After 6 months, the tai chi group showed substantially fewer falls (38 versus $73, p=0.007$ ) and significant improvements in measures of functional balance, physical performance and fear of falling. In a meta-analysis of four studies involving 1016 community-dwelling men and women aged 65 to 97 years, a home exercise training programme reduced the number of falls by $35 \%$, and in terms of injury prevention, participants aged $\geq 80$ years benefited significantly more than those aged 65 to 79 years $^{79}$.

Lack of motivation and fatigue can limit compliance and effectiveness of conventional exercise training. Whole-body vibration is emerging as a potentially promising alternative to conventional exercise for older people. Whole body vibration, and the reflexive muscle contraction it provokes, can induce similar strength gain to moderate intensity resistance training $^{80}$, and in postmenopausal women it can improve muscle strength and increase hip $\mathrm{BMD}^{81}$. In controlled studies in elderly nursing home residents, whole body vibration improved measures of body balance and performance in mobility tests such as the timed up-and-go test ${ }^{82,83}$. Whole body vibration may provide a means of reducing fall risk that is more acceptable to some elderly people than conventional exercise. However, to date no randomised controlled trial has assessed its effect on the numbers of falls.
Early studies suggested that wearing hip protectors reduced the incidence of hip fracture in elderly people living in institutional care. However, recent systematic reviews have indicated that hip protectors are not effective in community-dwelling individuals, and have cast doubt on their effectiveness in those living in institutions ${ }^{84,85}$. Patient adherence with hip protector use has been problematic and may have affected study results. However, a recent study in 1024 nursing home residents (mean age 85 years) found that hip protectors were not effective in reducing hip fracture both in the overall sample of participants and in the subgroup whose adherence to the study protocol was good $(>80 \% \text { adherence })^{86}$.

\section{Conclusions}

Fall risk depends on many factors, and it is to be expected that comprehensive, multifactorial risk assessment and reduction programmes should potentially offer the greatest benefits. However, such programmes may be difficult to implement effectively in clinical practice. Exercise programmes, especially those involving high doses of exercise and incorporating balance training, have been shown to be effective and may be easier to implement successfully.

\section{Vitamin D and calcium supplementation}

Vitamin D is known to be important in calcium and phosphorus absorption and homeostasis and is essential for the development and maintenance of bone strength $^{87,88}$. Additionally, in recent years increasing attention has been focussed on the importance of vitamin D in skeletal muscle function ${ }^{89-92}$.

Vitamin $\mathrm{D}$ is formed in the skin under the action of solar UV-B irradiation and is also obtained from the diet, notably from oily fish and egg yolk. Dietary and cutaneous vitamin D undergoes sequential hydroxylations in the liver and then in the kidney to produce the biologically active form ${ }^{87,88}$. Risk factors for vitamin D inadequacy include dietary deficiency and low exposure to sunlight, which may be due to lifestyle factors, living at high latitudes, cultural and religious practices of covering the skin surface, and skin pigmentation ${ }^{87}$. Elderly people have reduced capacity for cutaneous synthesis of vitamin D during skin exposure to UV radiation $^{93}$.

The most reliable means to assess vitamin D status is measurement of the serum concentration of its major circulating metabolite, 25(OH)D. Low serum $25(\mathrm{OH}) \mathrm{D}$ levels predict increased risk of hip fracture, 


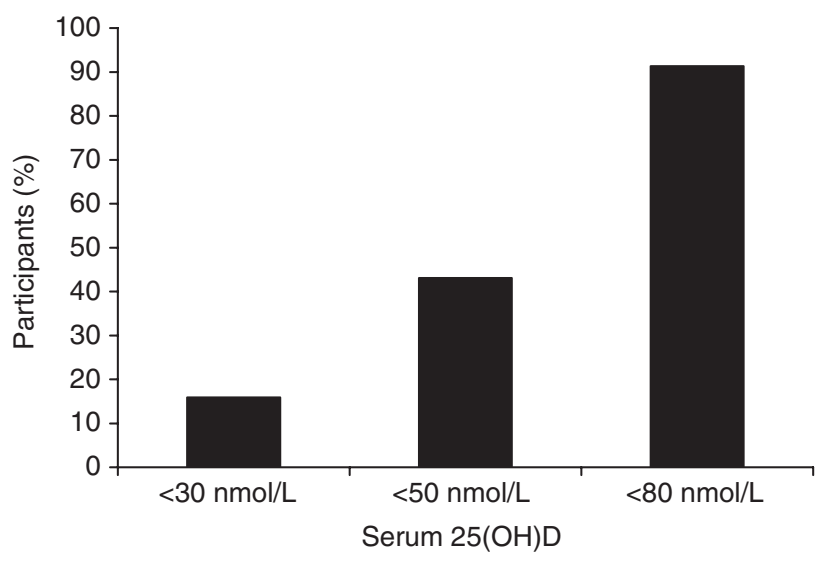

Figure 2. Serum 25-hydroxyvitamin D [25(OH)D] concentrations in 1195 Belgian postmenopausal women, levels $<80 \mathrm{nmol} / \mathrm{L}$ are considered below optimal; data from Neuprez et al. ${ }^{104}$

and the risk increases with decreasing quartiles of serum $25(\mathrm{OH}) \mathrm{D}^{94}$. Optimal serum 25(OH)D concentrations have not been defined precisely, but a consensus is emerging that an ideal level is between 80 and $100 \mathrm{nmol} / \mathrm{L}^{95}$, and the minimum desirable level is approximately $75 \mathrm{nmol} / \mathrm{L}^{95-98}$. Vitamin D inadequacy is highly prevalent in many countries, especially among women with osteoporosis ${ }^{99-102}$. In a recent study of men and women in a hospital rehabilitation unit (mean age 70 years) in the USA, 94\% had serum 25(OH)D levels below $80 \mathrm{nmol} / \mathrm{L}^{103}$. Similarly, in 1195 postmenopausal women with osteoporosis (mean age 76.9 years) in Belgium, 91\% had serum 25(OH)D levels below $80 \mathrm{nmol} / \mathrm{L}$ (Figure 2), and serum $25(\mathrm{OH}) \mathrm{D}$ concentration decreased significantly with age ${ }^{104}$.

At first sight, therefore, vitamin D supplementation, usually in combination with calcium ${ }^{105,106}$, offers a straightforward and inexpensive means of improving both sides of the bone strength/fall propensity balance. However, the large number of studies and metaanalyses evaluating the clinical effectiveness of vitamin $\mathrm{D}$ and calcium supplementation in preventing fractures have produced highly discrepant results.

One of the most compelling demonstrations of the effectiveness of vitamin D and calcium supplementation was also one of the earliest. Chapuy et al. ${ }^{107}$ treated 3270 elderly women (mean age 84 years) living in institutional care with either the combination of vitamin D3 (cholecalciferol 800 IU) and calcium phosphate $(1.2 \mathrm{~g}$ elemental calcium) or double placebo, daily for 18 months. Among women who completed the study, the number of hip fractures was reduced by $43 \%$ and all nonvertebral fractures were reduced by $32 \%$ in the supplementation group ${ }^{107}$. However, since this landmark study, numerous studies have come to opposite conclusions as to whether vitamin $\mathrm{D}$, with or without calcium, reduces fall and fracture risk in various populations. Meta-analyses have also produced differing conclusions depending on the subsets of studies they included. Nonetheless, five recent meta-analyses have been particularly instructive and will be described briefly.

\section{The meta-analysis of vitamin $D$ by Bischoff-Ferrari et al. ${ }^{108}$}

This meta-analysis included double-blind studies of supplementation with vitamin D with or without calcium, but studies that used active vitamin D metabolites were excluded. Meta-analyses involving all doses of vitamin $\mathrm{D}$ showed heterogeneity and indicated no effect on hip fracture (RR $0.88,96 \%$ CI 0.69 to 1.13). However, trials of high doses of vitamin D (700 to 800 IU per day), with or without calcium, showed homogeneity and significant reductions in hip fracture (RR $0.74,95 \%$ CI 0.61 to 0.88 ) and in any nonvertebral fracture (RR $0.77,95 \%$ CI 0.68 to 0.87 ).

\section{Calcium plus vitamin D supplementation in the Women's Health Initiative trial ${ }^{109}$}

A total of 36,282 healthy, community-dwelling, postmenopausal women (mean age 62.4 years) received $1 \mathrm{~g}$ elemental calcium and 400 IU vitamin D3 or placebo every day, with a mean follow-up of 7 years. In an intention-to-treat analysis, there was no significant treatment effect on hip, clinical vertebral or total fractures, and the incidence of kidney stones was increased significantly in the supplementation group (hazard ratio $1.17,95 \%$ CI 1.02 to 1.34 ). However, subgroup analyses showed significant reductions in hip fractures in women aged $\geq 60$ years (hazard ratio $0.79,95 \% \mathrm{CI}$ 0.64 to 0.98 ), and in women $>80 \%$ adherent to treatment (hazard ratio $0.71,95 \%$ CI 0.52 to 0.97 ).

\section{The meta-analysis of calcium or calcium in combination with vitamin $D$ by Tang et al. ${ }^{110}$}

Meta-analysis of 17 trials of calcium and calcium in combination with vitamin D $(52,625$ participants, 46,108 receiving the combination) indicated a $12 \%$ reduction in fractures of all types (RR 0.88, 95\% CI 0.83 to 0.95 ). Trials reporting compliance rates of $\geq 80 \%$ showed a greater treatment effect of $24 \%$. Treatment effect was also greater in people aged $>70$ years compared with those aged 50 to 70 years, and in those living in care institutions (RR 0.76) compared with those living in the community (RR 0.94). The benefit of treatment was also significantly greater 
with calcium doses $\geq 1200 \mathrm{mg}$ per day, or vitamin D doses $\geq 800 \mathrm{IU}$ per day.

\section{The Cochrane review of vitamin $D$ and related compounds ${ }^{111}$}

In a meta-analysis of eight trials involving 46,658 participants, the combination of vitamin $\mathrm{D}$ with calcium significantly reduced hip fractures (RR 0.84, 95\% CI 0.73 to 0.96 ), and a subgroup analysis suggested that the effect was significant among those living in institutional care. Meta-analysis of nine trials involving 24,749 participants suggested that vitamin $\mathrm{D}$ alone was unlikely to be effective in preventing hip fracture.

\section{Effect of vitamin D supplementation on falls ${ }^{112}$}

Meta-analysis of 5 trials (1237 participants, community dwelling or institutionalised) indicated that vitamin D supplementation (any form) reduced the risk of falling by $22 \%$ (corrected odds ratio $0.78,95 \%$ CI 0.64 to 0.92) compared with placebo or calcium alone. In a sensitivity analysis, inclusion of five additional trials that did not meet all the selection criteria (increasing the sample to 10,001 participants) resulted in a smaller, but still significant, reduction in risk of 13\% (corrected odds ratio $0.87,95 \%$ CI 0.80 to 0.96 ).

\section{Interpretation and implications}

These analyses indicate that vitamin D and calcium supplementation can be effective in preventing falls and fractures in elderly people, and we suggest several points that may be important in interpreting trial results and in optimising clinical use of vitamin D and calcium.

\section{Patient selection}

Vitamin D supplementation has no effect in vitamin D-replete patients, in part because negative feedback regulation means it will not be converted to the active form by the kidney. The likelihood of effectiveness of vitamin D and calcium supplementation increases with the degree of vitamin D inadequacy. People in care institutions are likely to have more risk factors and are more likely to show vitamin $\mathrm{D}$ inadequacy than those living in the community ${ }^{13,114}$. The effectiveness of vitamin D and calcium supplementation also appears to increase with age. However, it should be borne in mind that renal insufficiency is common in the elderly and may reduce conversion of vitamin $\mathrm{D}$ to the active form. Administration of an active vitamin D analogue may be effective in patients with renal insufficiency.

\section{Dose}

Vitamin D doses of $\geq 800$ IU per day seem more effective than lower doses, which were ineffective in some analyses. Furthermore, it has been estimated that higher doses of perhaps $2000 \mathrm{IU}$ per day might be required to bring $25(\mathrm{OH}) \mathrm{D}$ levels up to desirable levels in many elderly people ${ }^{98,115}$. Calcium doses of $\geq 1200 \mathrm{mg}$ per day also seem more effective than lower doses. However, excessive calcium intake may increase the risk of kidney stones in the general population, and might also increase the risk of vascular events in the elderly $^{116}$; these aspects and dietary calcium intake should be taken into account when prescribing calcium supplementation. Hypocalciuria is a good indication for calcium supplementation. Vitamin D inadequacy also interferes with phosphorus homeostasis; there may be a case for administering calcium supplementation in the form of calcium phosphate, as was done in the landmark Chapuy et al. study ${ }^{107}$.

\section{Adherence}

Poor adherence appears to be a major factor limiting the efficacy of vitamin D and calcium supplementation in clinical trials, and an even greater problem in clinical practice. In a recent study in 122 elderly hip fracture patients, 58 were taking vitamin D and calcium supplementation regularly or with occasional irregularity at 6 months after hospital discharge, but the number had fallen to 32 patients at 12 months and three patients at 2 years ${ }^{117}$. Adherence to vitamin D and calcium supplementation in clinical practice appears to be lower than for specific anti-osteoporotic drugs

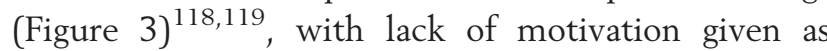
the most frequent reason for discontinuation ${ }^{119}$. Adherence to calcium supplementation may be lower than for vitamin D, partly because of gastrointestinal symptoms ${ }^{120}$. Inclusion of calcium supplementation or even both calcium and vitamin $\mathrm{D}$ in the same packet with co-prescribed anti-osteoporotic drugs may be beneficial $^{121,122}$.

\section{Conclusions}

An adequate supply of vitamin D and calcium is essential for the maintenance of bone strength and skeletal muscle function. Recent research indicates that that the minimum desirable serum 25(OH)D level is 75 to $80 \mathrm{nmol} / \mathrm{L}$. Many older people, especially the very elderly and those living in care institutions, are likely to have vitamin $\mathrm{D}$ inadequacy and insufficient dietary calcium intake. In appropriate patients and given in sufficient doses, vitamin D and calcium supplementation is effective in reducing falls and osteoporotic 


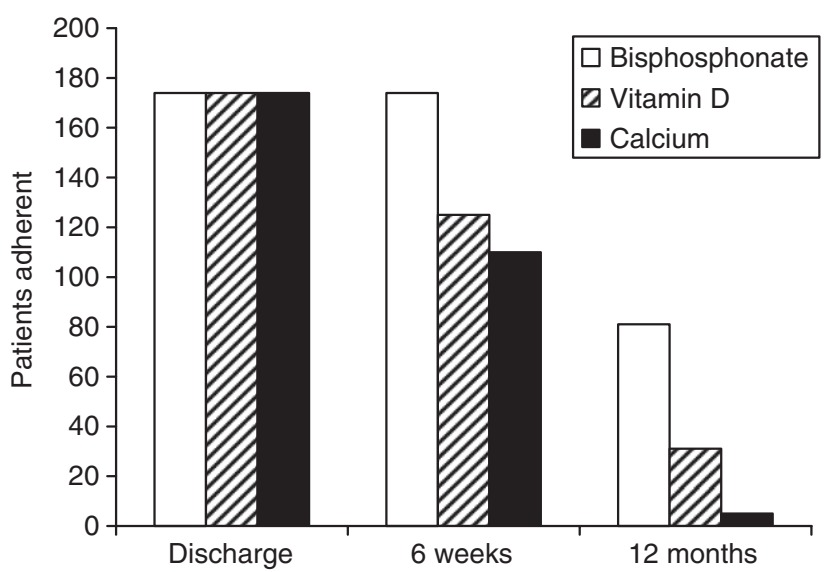

Figure 3. Adherence to anti-osteoporosis treatments after discharge from a rehabilitation programme following osteoporotic fracture, graph shows number of patients adherent to bisphosphonate therapy, vitamin D supplementation (400 IU per day) and calcium supplementation (2.5 g per day); data from Petrella and Jones ${ }^{118}$

fractures, including hip fractures. Normalisation of vitamin D levels (to a serum $25(\mathrm{OH}) \mathrm{D}$ concentration of at least $50 \mathrm{nmol} / \mathrm{L}$, ideally 75 to $80 \mathrm{nmol} / \mathrm{L}$ ) and calcium status should be regarded as basic therapy for all forms of osteoporosis ${ }^{106}$, and should be instigated together with any specific anti-osteoporosis medication. Vitamin D doses of 800 to 1000 IU per day or higher may be required to achieve this. The apparent discrepancies in the published literature should not discourage physicians from taking steps necessary to normalise vitamin $\mathrm{D}$ and calcium status.

\section{Specific anti-osteoporotic drugs}

The efficacy of several agents in increasing bone strength and reducing osteoporotic fracture risk has been established in a number of well-designed randomised clinical trials, largely carried out to meet regulatory requirements. However, most such trials have included only a small proportion of very elderly participants. We know of only two such randomised studies specifically designed to assess anti-fracture efficacy primarily in the very elderly population. Furthermore, evidence of efficacy has been generally most compelling for vertebral fractures. Evidence for nonvertebral fractures and particularly hip fracture, the most important and serious osteoporotic fracture in the very elderly, is more scant and less consistent ${ }^{123}$.

Specific anti-osteoporotic drugs are widely underused in people at risk of osteoporotic fracture ${ }^{124-129}$. In a recent study of 23,146 patients in Belgium

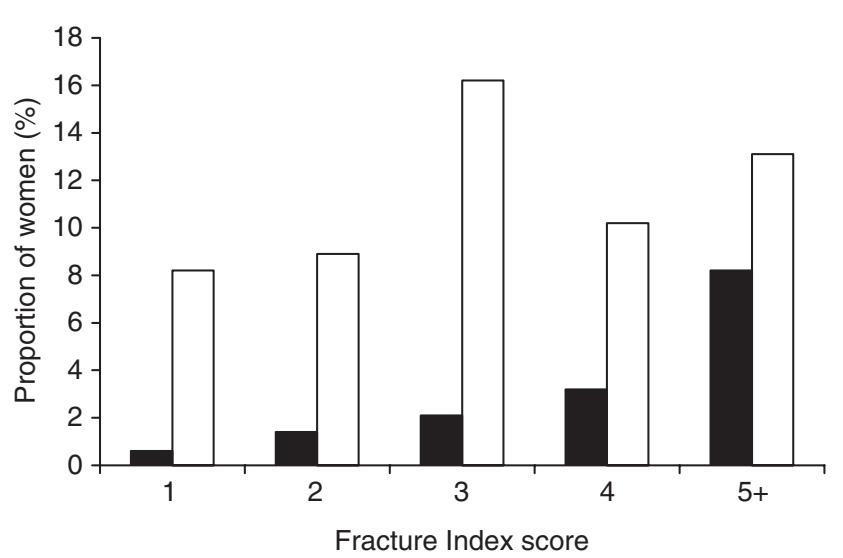

Figure 4. The proportion of women aged $\geq 65$ years likely to experience hip fracture within 5 years (filled columns) rises exponentially with Fracture Index score, but this increase in risk is not reflected in the proportion receiving specific antiosteoporotic drug treatment (hollow columns); data from Gehlbach et al. ${ }^{131}$

hospitalised for hip fracture, only $6 \%$ of those not previously treated received a specific anti-osteoporotic drug after the fracture ${ }^{130}$. Data from the US National Health and Nutrition Examination Survey (NHANES), showed that only $12 \%$ of women aged $\geq 85$ years, and $17 \%$ of women aged $\geq 65$ years who had a history of fracture, were receiving treatment targeted to prevent bone loss ${ }^{131}$. Anti-osteoporosis treatment is not always targeted at those at greatest risk of fracture. Women in the NHANES study were assessed for fracture risk using the Fracture Index ${ }^{132}$; it was found that rates of anti-osteoporotic drug use did not increase progressively with fracture risk and only $13 \%$ of those in the highest risk category received such treatment (Figure 4$)^{131}$. In another study in women aged $\geq 60$ years with hip, vertebral or wrist fracture, increasing age was associated with a reduced likelihood of receiving specific anti-osteoporosis treatment ${ }^{126}$. Finally, among elderly patients admitted to a nursing home after a hip, wrist, or humeral fracture, only $18.7 \%$ received an anti-osteoporosis medication in 2001, and this rate showed no improvement between 2001 and $2004^{133}$. The relative lack of direct evidence of benefit, particularly against nonvertebral and hip fractures, in the very elderly may have contributed to these low rates of usage. A further factor may be concern that anti-osteoporotic drug treatment requires a long time to take effect, which must be weighed against the life expectancy of some of those at greatest risk.

\section{Efficacy of anti-osteoporotic drugs in the very elderly}

Evidence of efficacy of anti-osteoporotic drugs in the very elderly has come primarily from subgroup 
Table 3. Summary of analyses demonstrating anti-fracture efficacy of anti-osteoporotic drugs in very elderly people, based on data from Inderjeeth et al. ${ }^{134}$

\begin{tabular}{|c|c|c|c|c|}
\hline \multirow[t]{2}{*}{ Drug: study; target population; mean age } & \multicolumn{2}{|c|}{ 1-year results } & \multicolumn{2}{|c|}{3 -year results } \\
\hline & RRR & $p$-value & RRR & $p$-value \\
\hline \multicolumn{5}{|c|}{$\begin{array}{l}\text { Strontium ranelate: pooled analysis of data from two } \mathrm{RCTs}^{11} \text {; } \\
\quad \text { women } \geq 80 \text { years; mean age } 83.5 \text { years }\end{array}$} \\
\hline Hip fracture & - & - & {$[32 \%]$} & NS \\
\hline Nonvertebral fracture & $41 \%$ & 0.027 & $31 \%$ & 0.011 \\
\hline Vertebral fracture & $59 \%$ & 0.002 & $32 \%$ & 0.013 \\
\hline \multicolumn{5}{|c|}{$\begin{array}{l}\text { Strontium ranelate: subgroup analysis of TROPOS study }{ }^{137} \text {; high } \\
\quad \text { risk women } \geq 74 \text { years; mean age } 79.2 \text { years }\end{array}$} \\
\hline Hip fracture & - & - & $36 \%$ & 0.046 \\
\hline \multicolumn{5}{|c|}{ Alendronate: subgroup analysis of FIT study ${ }^{138}$; women $\geq 75$ years } \\
\hline Vertebral fracture & - & - & $38 \%$ & $<0.05$ \\
\hline \multicolumn{5}{|c|}{$\begin{array}{l}\text { Risedronate: subgroup analysis of HIP study }{ }^{140} \text {; women } \geq 80 \text { years; } \\
\text { mean age } 83 \text { years }\end{array}$} \\
\hline Hip fracture & - & - & [20\%] & NS \\
\hline \multicolumn{5}{|c|}{$\begin{array}{l}\text { Risedronate: pooled analysis of data from three } \mathrm{RCT}^{143} \text {; women } \\
\quad \geq 80 \text { years; mean age } 83.0 \text { years }\end{array}$} \\
\hline Hip fracture & - & - & - & - \\
\hline Nonvertebral fracture & - & - & [?] & NS \\
\hline Vertebral fracture & $81 \%$ & $<0.001$ & $44 \%$ & 0.003 \\
\hline \multicolumn{5}{|c|}{$\begin{array}{l}\text { Clodronate: } \mathrm{RCT}^{144} \text {; women } \geq 75 \text { years, not selected for } \\
\text { osteoporosis, mean age } 80 \text { years }\end{array}$} \\
\hline Hip fracture & [HR 1.31] & NS & [HR 1.02] & NS \\
\hline Nonhip fracture & - & - & $29 \%$ & 0.001 \\
\hline \multicolumn{5}{|c|}{$\begin{array}{l}\text { Teriparatide: subgroup analysis of FPT study }{ }^{147} \text {; women } \geq 75 \text { years; } \\
\text { mean age } 78 \text { years }\end{array}$} \\
\hline Nonvertebral fracture & {$[25 \%]$} & NS & - & - \\
\hline Vertebral fracture & $65 \%$ & $<0.05$ & - & - \\
\hline
\end{tabular}

HR: hazard ratio; NS: not significant; RCT: randomised controlled trial; RRR: relative risk reduction

Study name abbreviations - FIT: Fracture Intervention Trial; FPT: Fracture Prevention Trial; HIP: Hip Intervention Program trial; TROPOS:

TReatment Of Peripheral OSteoporosis trial

analyses, in some cases involving the pooling of data from more than one trial. A literature search and review of published evidence has been published recently $^{134}$, as has a less formal analysis ${ }^{135}$. In light of these recent articles, only a relatively brief summary will be given here.

\section{Strontium ranelate}

Perhaps the most complete body of evidence of antifracture efficacy in the very elderly is for the relatively recently introduced drug, strontium ranelate. A preplanned pooled analysis of data from women aged $\geq 80$ years ${ }^{11}$ taken from two large trials ${ }^{136,137}$ showed significant reductions in relative risk of vertebral and nonvertebral fractures at 3 years of $32 \%(p=0.013)$ and $31 \%(p=0.011)$, respectively (Table 3$)$. As early as 1 year into treatment there were significant reductions in vertebral and nonvertebral fractures of 59\% and
$41 \%$, respectively. The reduction in hip fracture risk at 3 years was $32 \%$, but did not reach statistical significance. However, a subgroup analysis of high-risk women aged $\geq 74$ years in the TROPOS study showed a significant risk reduction of $36 \%$ at 3 years $^{137}$.

\section{Alendronate}

In a post hoc analysis of the Fracture Intervention Trial, alendronate was associated with a $38 \%$ reduction in risk of vertebral fracture at 3 years in women aged $\geq 75$ years (Table 3$)^{138}$. Data from this trial were used to calculate age-specific fracture rates in the alendronate and placebo groups using a Cox proportional hazards regression model ${ }^{139}$, which suggested that the effect of alendronate on symptomatic vertebral and hip fractures was approximately constant across the age range of women in the study. No data are available in patients $\geq 80$ years. 


\section{Risedronate}

In the Hip Intervention Program ${ }^{140}$, risedronate had no effect on the incidence of hip fracture in the subgroup of women aged $\geq 80$ years. In a pooled analysis of data for women aged $\geq 80$ years from three trials, the Hip Intervention Program and the two Vertebral Efficacy with Risedronate Therapy trials ${ }^{141,142}$, risedronate dramatically reduced the incidence of vertebral fracture by $81 \%$ at 1 year and $44 \%$ at 3 years, but had no effect on nonvertebral fractures (Table 3$)^{143}$. Hip fractures were not reported separately in this analysis.

\section{Ibandronate}

No data are available on the antifracture efficacy of ibandronate in the very elderly.

\section{Clodronate}

The efficacy of clodronate was evaluated in a study in randomly selected community-dwelling women aged $\geq 75$ years who did not need to have osteoporosis or any other known risk factors for fracture ${ }^{144}$. Over 3 years, clodronate had no effect on the incidence of hip fracture (hazard ratio 1.02, $p=0.918$; Table 3 ). Interestingly, at 1 year, the hip fracture rate was numerically higher in the clodronate group $(0.86 \%)$ than in the placebo group $(0.61 \%$; hazard ratio 1.31 , not significant). However, clodronate treatment did reduce the risk of any clinical fracture by $20 \%$ (hazard ratio $0.80,95 \%$ CI 0.68 to 0.94 ) and nonhip fractures by $29 \%$ (hazard ratio $0.71,95 \%$ CI 0.57 to 0.87 ) at 3 years. No data are available in patients $\geq 80$ years.

\section{Zoledronic acid}

Although not yet formally evaluated in the very elderly, once-yearly zoledronic acid reduced rates of vertebral and nonvertebral fractures in patients (mean age 74.5 years) with recent hip fracture, although the reduction in hip fractures was not significant ${ }^{145}$. Interestingly, the rate of death was reduced by $28 \%$ in the zoledronic acid group, emphasising the impact of osteoporotic fractures on mortality.

\section{Teriparatide}

In a subgroup analysis of data from women aged $\geq 75$ years in the Fracture Prevention Trial ${ }^{146}$, teriparatide treatment was associated with a significant $65 \%$ reduction in risk of new vertebral fracture, but had no effect on nonvertebral fractures after a median treatment duration of 19 months (Table 3$)^{147}$. Hip fractures were not reported separately in this analysis, and no data are available for teriparatide in patients $\geq 80$ years.

\section{Non-adherence to treatment}

Non-adherence is a substantial problem with specific anti-osteoporotic therapy in clinical practice ${ }^{148-151}$. In one study in 18,822 women, the overall risk of nonadherence (defined as medication days $<80 \%$ of those possible) was $47 \%$ at 3 months, $70 \%$ at 1 year and $84 \%$ at 3 years ${ }^{152}$. Older age may predict a greater risk of non-adherence ${ }^{149,153}$. Several recent studies have shown that non-adherence is associated with significantly elevated risk of vertebral and nonvertebral fracture $^{154-157}$. Studies evaluating interventions to improve general medication adherence in older people have yielded only mixed results ${ }^{158,159}$.

A further issue for very elderly individuals is the need to meet the specific requirements for oral intake of bisphosphonates (fasting before and after intake, not sucking or chewing tablets, taking with a full glass of water, remaining upright for 30-60 minutes after intake) to prevent adverse effects on the mouth and oesophagus. These requirements are not adhered to by a substantial minority of patients generally ${ }^{160}$, and may be particularly challenging for the very elderly. Intermittent dosing regimens for bisphosphonates may have the potential to reduce the inconvenience associated with daily oral dosing and could improve adherence to therapy ${ }^{148,150,161}$, although not all studies have shown this ${ }^{152}$ and adherence rates remain severely suboptimal. Weekly oral alendronate and risedronate, and ibandronate given orally at monthly intervals or intravenously every 2 or 3 months, have been evaluated $^{162-164}$, as well as once-yearly zoledronic $\operatorname{acid}^{145,165}$, although the efficacy of these regimens in the very elderly has not yet been established.

\section{Conclusions}

It could be argued that the preceding discussion essentially documents severe undertreatment of elderly individuals, especially those most at risk of osteoporotic fractures, perhaps linked to the incomplete evidence base for most established anti-osteoporotic drugs in the very elderly, and compounded by inconvenience of oral dosing of bisphosphonates, poor adherence to anti-osteoporotic treatment generally, and concerns over the slow onset of benefit. However, the relatively recently introduced agent, strontium ranelate, has rapidly acquired an evidence base for its efficacy against hip and other nonvertebral fractures as well as vertebral fractures in the very elderly, and is given by a simple daily oral dosing regimen without the special precautions associated with bisphosphonates. Unlike other anti-osteoporotic drugs, strontium ranelate has also 
shown substantial efficacy against nonvertebral fractures in the elderly after 1 year of treatment, which may allay physician concerns about initiating therapy in very elderly or frail patients with a relatively short life expectancy. The evidence base for some other drugs in the very elderly is likely to increase in the coming years.

\section{Overall conclusions}

The risk of osteoporotic fractures in the very elderly is determined by a large number of factors ranging from hazards in the home environment to frailty, poor balance and bone fragility. This range of factors opens up numerous opportunities for intervention to reduce risk. However, each of the possible avenues for risk reduction has limitations or difficulties of implementation in clinical practice. Many are only suitable for selected patients, and in most cases the evidence base is less complete and less compelling than one would like. Attempting to pursue all possible avenues in every individual would result in expensive, unwieldy and probably ineffective treatment programmes. However, the present situation in which many elderly people at high risk of fracture receive no treatment or highly inadequate treatment is equally unacceptable. The major limitation of this article is that our review was not systematic and involved a degree of judgement and opinion on the part of the authors, necessitated in part by the volume and complexity of the published evidence. Nonetheless, we believe that the research summarised here indicates that effective treatments are available, including exercise training, vitamin $\mathrm{D}$ and calcium supplementation, and use of evidence-based anti-osteoporotic drugs, which can be appropriate for a high proportion of elderly individuals. A positive and determined approach to optimising the use of such treatments could help to reduce the large and increasing burden of osteoporotic fractures in the very elderly.

\section{Transparency}

\section{Declaration of funding}

The European Society for Clinical and Economical Aspects of Osteoporosis and Osteoarthritis (ESCEO), funded, through an unrestricted educational grant, the Experts' consensus meeting and the preparation of the manuscript. Servier International agreed to fund the publication support of the article after submission of the manuscript but were not involved in its preparation or drafting, for which the authors take full responsibility.

\section{Declaration of financial/other interests}

The authors are all members of ESCEO - a society that has been the recipient of unrestricted educational grants from
Servier. R.R. has disclosed that he is a consultant/advisor to Merck, Roche, Servier, Danone, Nycomed, Eli Lilly and Amgen; and that he is on the speakers bureau for Roche, Novartis, Servier and Amgen. O.B. has disclosed that he has been the recipient of sponsorship/research funding from Servier, MSD, GlaxoSmithKline, Theramex, Rottapharm; and that he is a consultant/advisor to Servier, GlaxoSmithKline, Galapagos NV, Rottapharm. J.B.C.-A. has disclosed that he is a consultant/advisor to Shire, and is on the speakers bureau for Servier, Shire and Amgen. J.-P.D. has disclosed that he has received research grant funding from Novartis and Schering-Plough; that he is a consultant/advisor for Novartis; and that he is on the speakers bureau for Eli Lilly, Servier and Novartis. G.L. has disclosed that he has no relevant financial relationships. J.D.R. has disclosed that he is a consultant/advisor for Novartis, Merck, Amgen, Servier; and that he is on the speakers bureau for Merck, Procter \& Gamble, Roche, Amgen and Servier. B.V. has disclosed that he is a consultant/advisor for Servier. J.-Y.R. has disclosed that he has been the recipient of research grants from Bristol Myers Squibb, Merck Sharp \& Dohme, Rottapharm, Teva, Lilly, Novartis, Roche, GlaxoSmithKline, Amgen, Servier; that he is a consultant/ advisor to Servier, Novartis, Negma, Lilly, Wyeth, Amgen, GlaxoSmithKline, Roche, Merckle, Nycomed, NPS, Theramex, UCB; and that he has been the recipient of lecture fees for speaking at meetings on behalf of Merck Sharp and Dohme, Lilly, Rottapharm, IBSA, Genevrier, Novartis, Servier, Roche, GlaxoSmithKline, Teijin, Teva, Ebewee Pharma, Zodiac, Analis, Theramex, Nycomed, NovoNordisk.

All peer reviewers receive honoraria from CMRO for their review work. Peer Reviewer 1 has disclosed that he/she has no relevant financial relationships. Peer Reviewer 2 has disclosed that he has been the recipient of grant/research support from Amgen, Eli Lilly, GSK, Novartis, Pfizer, Procter \& Gamble, Roche, sanofi Aventis, Wyeth; that he is on the speakers bureau and the advisory board for Eli Lilly, Novartis, Roche/GSK; that he is on the advisory board for Amgen, Upsher-Smith and Wyeth; and that he is a direct stockholder in Procter \& Gamble and Teva.

Acknowledgements

The authors thank Mr Alan Larkman for his help in preparing this review. This assistance was funded by ESCEO.

\section{References}

1. Burge R, Dawson-Hughes B, Solomon DH, et al. Incidence and economic burden of osteoporosis-related fractures in the United States, 2005-2025. J Bone Miner Res 2007;22:465-75

2. Johnell O, Kanis JA. An estimate of the worldwide prevalence, mortality and disability associated with hip fracture. Osteoporos Int 2004; 15:897-902

3. Haleem S, Lutchman L, Mayahi R, et al. Mortality following hip fracture: trends and geographical variations over the last 40 years. Injury 2008;39:1157-63

4. Abrahamsen B, van Staa T, Ariely R, et al. Excess mortality following hip fracture: a systematic epidemiological review. Osteoporos Int 2009 May 7 [Epub ahead of print]

5. Maravic M, Le Bihan C, Landais $P$, et al. Incidence and cost of osteoporotic fractures in France during 2001: a methodological approach by the national hospital database. Osteoporos Int 2005; 16:1475-80 
6. Morosano M, Masoni A, Sánchez A. Incidence of hip fractures in the city of Rosario, Argentina. Osteoporos Int 2005;16:1339-44

7. Cummings SR, Melton 3rd LJ. Epidemiology and outcomes of osteoporotic fractures. Lancet 2002;359:1761-7

8. Chang KP, Center JR, Nguyen TV, et al. Incidence of hip and other osteoporotic fractures in elderly men and women: Dubbo Osteoporosis Epidemiology Study. J Bone Miner Res 2004;19:532-6

9. Holroyd C, Cooper C, Dennison E. Epidemiology of osteoporosis. Best Pract Res Clin Endocrinol Metab 2008;22:671-85

10. Couris CM, Ducios A, Rabilloud M, et al. A seventy percent overestimation of the burden of hip fractures in women aged 85 and over. Bone 2007;41:896-900

11. Seeman E, Vellas B, Benhamou C, et al. Strontium ranelate reduces the risk of vertebral and nonvertebral fractures in women eighty years of age and older. J Bone Miner Res 2006; 21:1113-20

12. Chevalley T, Guilley E, Herrmann FR, et al. Incidence of hip fracture over a 10-year period (1991-2000): reversal of a secular trend. Bone 2007;40:1284-9

13. Holt G, Smith R, Duncan K, et al. Epidemiology and outcome after hip fracture in the under $65 \mathrm{~s}$ - evidence form the Scottish Hip Fracture Audit. Injury Int J Care Injured 2008;39:1175-81

14. Melton 3rd LJ, Kearns AE, Atkinson EJ, et al. Secular trends in hip fracture incidence and occurrence. Osteoporos Int 2009; 20:687-94

15. Berry SD, Samelson EJ, Hannan MT, et al. Second hip fracture in older men and women: the Framingham Study. Arch Intern Med 2007;167:1971-6

16. Ryg J, Rejnmark L, Overgaard S, et al. Hip fracture patients at risk of second hip fracture - a nationwide population-based cohort study of 169,145 cases during 1977-2001. J Bone Miner Res 2009;24:1299-307

17. Kanis JA, Johnell O, Oden A, et al. Ten year probabilities of osteoporotic fractures according to BMD and diagnostic thresholds. Osteoporos Int 2001;12:989-95

18. Schuit SC, van der Klift M, Weel AE, et al. Fracture incidence and association with bone mineral density in elderly men and women: the Rotterdam Study. Bone 2004;34:195-202

19. Wainwright SA, Marshall LM, Ensrud KE, et al.; Study of Osteoporotic Fractures Research Group. Hip fracture in women without osteoporosis. J Clin Endocrinol Metab 2005;90:2787-93

20. Sanders KM, Nicholson GC, Watts JJ, et al. Half the burden of fragility fractures in the community occur in women without osteoporosis. When is fracture prevention cost-effective? Bone 2006;38:694-700

21. Järvinen TL, Sievänen $H$, Khan KM, et al. Shifting the focus in fracture prevention from osteoporosis to falls. BMJ 2008; 336:124-6

22. Parkkari J, Kannus P, Palvanen M, et al. Majority of hip fractures occur as a result of a fall and impact on the greater trochanter of the femur: a prospective controlled hip fracture study with 206 consecutive patients. Calcif Tissue Int 1999;65:183-7

23. Youm T, Koval KJ, Kummer FJ, et al. Do all hip fractures result from a fall? Am J Orthop 1999;28:190-4

24. Cooper C, Atkinson EJ, O'Fallon WM, et al. Incidence of clinically diagnosed vertebral fractures: a population-based study in Rochester, Minnesota, 1985-1989. J Bone Miner Res 1992; 7:221-7

25. Birge SJ. Osteoporotic fractures: a brain or bone disease? Curr Osteoporos Rep 2008;6:57-61

26. Bergman H, Ferrucci L, Guralnik J, et al. Frailty: an emerging research and clinical paradigm - issues and controversies. J Gerontol A Biol Sci Med Sci 2007;62:731-7

27. Fried LP, Tangen CM, Walston J, et al.; Cardiovascular Health Study Collaborative Research Group. Frailty in older adults: evidence for a phenotype. J Gerontol A Biol Sci Med Sci 2001;56:M146-M156

28. Fried LP, Ferrucci L, Darer J, et al. Untangling the concepts of disability, frailty, and comorbidity: implications for improved targeting and care. J Gerontol A Biol Sci Med Sci 2004; 59:255-63

29. Boyd CM, Xue QL, Simpson CF, et al. Frailty, hospitalization, and progression of disability in a cohort of disabled older women. Am J Med 2005; 118:1225-31

30. Woods NF, LaCroix AZ, Gray SL; Women's Health Initiative. J Am Geriatr Soc 2005;53:1321-30

31. Bandeen-Roche K, Xue QL, Ferrucci L, et al. Phenotype of frailty: characterization in the women's health and aging studies. J Gerontol A Biol Sci Med Sci 2006;61:262-6

32. Cawthon PM, Marshall LM, Michael Y, et al.; Osteoporotic Fractures in Men Research Group. Frailty in older men: prevalence, progression, and relationship with mortality. J Am Geriatr Soc 2007;55:1216-23

33. Ensrud KE, Ewing SK, Taylor BC, et al.; for the Study of Osteoporotic Fractures Research Group. Frailty and risk of falls, fracture, and mortality in older women: the study of osteoporotic fractures. J Gerontol A Biol Sci Med Sci 2007; 62:744-51

34. Avila-Funes JA, Helmer, C, Amieva H, et al. Frailty among community-dwelling elderly people in France: the three-city study. J Gerontol A Biol Sci Med Sci 2008;63:1089-96

35. Santos-Eggimann B, Cuénoud P, Spagnoli J, et al. Prevalence of frailty in middle-aged and older community-dwelling Europeans living in 10 countries. J Gerontol A Biol Sci Med Sci 2009;64:675-81

36. Rothman MD, Leo-Summers L, Gill TM. Prognostic significance of potential frailty criteria. J Am Geriatr Soc 2008; 56:2211-16

37. Avila-Funes JA, Amieva H, Barberger-Gateau P, et al. Cognitive impairment improves the predictive validity of the phenotype of frailty for adverse health outcomes: the three-city study. J Am Geriatr Soc 2009;57:453-61

38. Ensrud KE, Ewing SK, Taylor BC, et al.; for the Study of Osteoporotic Fractures Research Group. Comparison of 2 frailty indexes for prediction of falls, disability, fractures, and death in older women. Arch Intern Med 2008;168:382-9

39. Wagner H, Melhus H, Gedeborg R, et al. Simply ask them about their balance - future fracture risk in a nationwide cohort study of twins. Am J Epidemiol 2009; 169:143-9

40. Olofsson B, Stenvall M, Lundström M, et al. Malnutrition in hip fracture patients: an intervention study. J Clin Nurs 2007; $16: 2027-38$

41. Salminen H, Sääf M, Johansson SE, et al. Nutritional status, as determined by the Mini-Nutritional Assessment, and osteoporosis: a cross-sectional study of an elderly female population. Eur J Clin Nutr 2006;60:486-93

42. Walston J, Hadley EC, Ferrucci L, et al. Research agenda for frailty in older adults: toward a better understanding of physiology and etiology: summary from the American Geriatrics Society/National Institute on Aging Research Conference on Frailty in Older Adults. J Am Geriatr Soc 2006;54:991-1001

43. Howard C, Ferrucci L, Sun K, et al. Oxidative protein damage is associated with poor grip strength among older women living in the community. J Appl Physiol 2007;103:17-20

44. Ershler WB, Keller ET. Age-associated increased interleukin-6 gene expression, late-life diseases, and frailty. Annu Rev Med 2000;51:245-70

45. Ershler WB. A gripping reality: oxidative stress, inflammation, and the pathway to frailty. J Appl Physiol 2007;103:3-5

46. Leng SX, Xue QL, Tian J, et al. Inflammation and frailty in older women. J Am Geriatr Soc 2007;55:864-71

47. Puts MT, Visser M, Twisk JW, et al. Endocrine and inflammatory markers as predictors of frailty. Clin Endocrinol (Oxf) 2005;63:403-11

48. Walston J, Fedarko N, Yang H, et al. The physical and biological characterization of a frail mouse model. J Gerontol A Biol Sci Med Sci 2008;63:391-8

49. Gill TM, Gahbauer EA, Allore HG, et al. Transitions between frailty states among community-living older persons. Arch Intern Med 2006;166:418-23 
50. Kannus P, Sievänen $H$, Palvanen $M$, et al. Prevention of falls and consequent injuries in elderly people. Lancet 2005; 366:1885-93

51. O'Loughlin JL, Robitaille Y, Boivin JF, et al. Incidence of and risk factors for falls and injurious falls among the communitydwelling elderly. Am J Epidemiol 1993;137:342-54

52. Vellas BJ, Wayne SJ, Garry PJ, et al. A two-year longitudinal study of falls in 482 community-dwelling elderly adults. J Gerontol A Biol Sci Med Sci 1998;53:M264-M274

53. American Geriatrics Society, British Geriatrics Society, and American Academy of Orthopaedic Surgeons Panel on Falls Prevention. Guideline for the prevention of falls in older persons. J Am Geriatr Soc 2001;49:664-72

54. Rao SS. Prevention of falls in older patients. Am Fam Physician 2005;72:81-8

55. Stevens JA, Mack KA, Paulozzi LJ, et al. Self-reported falls and fall-related injuries among persons aged $\geq 65$ years - United States, 2006. J Safety Res 2008;39:345-9

56. Tinetti ME, Williams CS. Falls, injuries due to falls, and the risk of admission to a nursing home. N Engl J Med 1997; 337:1279-84

57. Sattin RW, Lambert Huber DA, DeVito CA, et al. The incidence of fall injury events among the elderly in a defined population. Am J Epidemiol 1990;131:1028-37

58. Kannus P, Parkkari J, Koskinen S, et al. Fall-induced injuries and deaths among older adults. JAMA 1999;281:1895-9

59. Winner SJ, Morgan CA, Evans JG. Perimenopausal risk of falling and incidence of distal forearm fracture. BMJ 1989;298:1486-8

60. Davies JC, Stevens G, Manning DP. An investigation of underfoot accidents in a MAIM (Merseyside Accident Information Model) database. Appl Ergon 2001;32:141-7

61. Davies JC Manning DP, Kemp GJ, et al. The rising number of underfoot accidents after the menopause causes both fractures and non-fracture injuries. QJ Med 2001;94:699-707

62. Scuffham P, Chaplin S, Legood R. Incidence and costs of unintentional falls in older people in the United Kingdom. J Epidemiol Community Health 2003;57:740-4

63. Leipzig RM, Cumming RG, Tinetti ME. Drugs and falls in older people: a systematic review and meta-analysis: I. Psychotropic drugs. J Am Geriatr Soc 1999; 47:30-9

64. Leipzig RM, Cumming RG, Tinetti ME. Drugs and falls in older people: a systematic review and meta-analysis: II. Cardiac and analgesic drugs. J Am Geriatr Soc 1999;47:40-50

65. Landi F, Onder G, Cesari M, et al.; Silver Network Home Care Study Group. Psychotropic medications and risk for falls among community-dwelling frail older people: an observational study. J Gerontol A Biol Sci Med Sci 2005;60:622-6

66. Rubenstein LZ. Falls in older people: epidemiology, risk factors and strategies for prevention. Age Ageing 2006;35 (Suppl. 2):ii37-ii41

67. Gates S, Fisher JD, Cooke MW, et al. Multifactorial assessment and targeted intervention for preventing falls and injuries among older people in community and emergency care settings: systematic review and meta-analysis. BMJ 2008; 336:130-3

68. Gillespie LD, Gillespie WJ, Robertson MC, et al. Interventions for preventing falls in elderly people. Cochrane Database Syst Rev 2003;2:CD000340

69. Gillespie LD, Robertson MC, Gillespie WJ, et al. Interventions for preventing falls in older people living in the community. Cochrane Database Syst Rev 2009;2:CD007146

70. Close J, Ellis M, Hooper R, et al. Prevention of falls in the elderly trial (PROFET): a randomised controlled trial. Lancet 1999; 353:93-7

71. Hendriks MR, Bleijlevens MH, van Haastregt JC, et al. Lack of effectiveness of a multidisciplinary fall-prevention program in elderly people at risk: a randomized, controlled trial. J Am Geriatr Soc 2008;56:1390-7

72. Lin MR, Wolf SL, Hwang HF, et al. A randomized, controlled trial of fall prevention programs and quality of life in older fallers. J Am Geriatr Soc 2007;55:499-506
73. Sherrington C, Whitney JC, Lord SR, et al. Effective exercise for the prevention of falls: a systematic review and meta-analysis. J Am Geriatr Soc 2008;56:2234-43

74. Bérard A, Bravo G, Gauthier P. Meta-analysis of the effectiveness of physical activity for the prevention of bone loss in postmenopausal women. Osteoporos Int 1997;7:331-7

75. Wolff I, van Croonenborg JJ, Kemper HC, et al. The effect of exercise training programs on bone mass: a meta-analysis of published controlled trials in pre- and postmenopausal women. Osteoporos Int 1999;9:1-12

76. Shea B, Bonaiuti D, Iovine R, et al. Cochrane Review on exercise for preventing and treating osteoporosis in postmenopausal women. Eura Medicophys 2004;40:199-209

77. Murphy MH, Nevill AM, Murtagh EM, et al. The effect of walking on fitness, fatness and resting blood pressure: a metaanalysis of randomised, controlled trials. Prev Med 2007;44: $377-85$

78. Li F, Harmer P, Fisher KJ, et al. Tai Chi and fall reductions in older adults: a randomised controlled trial. J Gerontol A Biol Sci Med Sci 2005;60:187-94

79. Robertson MC, Campbell AJ, Gardner MM, et al Preventing injuries in older people by preventing falls: a metaanalysis of individual-level data. J Am Geriatr Soc 2002;50: 905-11

80. Delecluse C, Roelants M, Verschueren S. Strength increase after whole-body vibration compared with resistance training. Med Sci Sports Exerc 2003;35:1033-41

81. Verschueren SM, Roelants M, Delecluse C, et al. Effect of 6 -month whole body vibration training on hip density, muscle strength, and postural control in postmenopausal women: a randomized controlled pilot study. J Bone Miner Res 2004; 19:352-9

82. Bautmans I, Van Hees E, Lemper JC, et al. The feasibility of Whole Body Vibration in institutionalised elderly persons and its influence on muscle performance, balance and mobility: a randomised controlled trial [ISRCTN62535013]. BMC Geriatr 2005;5:17

83. Bruyère $\mathrm{O}$, Wuidart MA, Di Palma $\mathrm{E}$, et al. Controlled whole body vibration to decrease fall risk and improve health-related quality of life of nursing home residents. Arch Phys Med Rehabil 2005;86:303-7

84. Parker MJ, Gillespie WJ, Gillespie LD. Hip protectors for preventing hip fractures in older people. Cochrane Database Syst Rev 2005;3:CD001255

85. Parker MJ, Gillespie WJ, Gillespie LD. Effectiveness of hip protectors for preventing hip fractures in elderly people: systematic review. BMJ 2006;332:571-4

86. Kiel DP, Magaziner J, Zimmerman S, et al. Efficacy of a hip protector to prevent hip fracture in nursing home residents: the HIP PRO randomized controlled trial. JAMA 2007; 298:413-22

87. Holick MF. High prevalence of vitamin D inadequacy and implications for health. Mayo Clin Proc 2006;81:353-73

88. Lips P. Vitamin D physiology. Prog Biophys Mol Biol 2006; 92:4-8

89. Boland R. Role of vitamin D in skeletal muscle function. Endocr Rev 1986;7:434-48

90. Visser M, Deeg DJ, Lips P; Longitudinal Aging Study Amsterdam. Low vitamin D and high parathyroid hormone levels as determinants of loss of muscle strength and muscle mass (sarcopenia): the Longitudinal Aging Study Amsterdam. J Clin Endocrinol Metab 2002;88:5766-72

91. Bischoff-Ferrari HA, Dietrich T, Orav EJ, et al. Higher 25-hydroxyvitamin $\mathrm{D}$ concentrations are associated with better lower-extremity function in both active and inactive persons aged $\geq 65$ y. Am J Clin Nutr 2004:80:752-8

92. Ceglia L. Vitamin D and skeletal muscle tissue and function Mol Aspects Med 2008;29:407-14

93. MacLaughlin J, Holick MF. Aging decreases the capacity of human skin to produce vitamin D3. J Clin Invest 1985; 76:1536-8 
94. Cauley JA, Lacroix AZ, Wu L, et al. Serum 25-hydroxyvitamin $\mathrm{D}$ concentrations and risk for hip fracture. Ann Intern Med 2008; 149:242-50

95. Bischoff-Ferrari HA, Giovannucci E, Willett WC, et al. Estimation of optimal serum concentrations of 25-hydroxyvitamin D for multiple health outcomes. Am J Clin Nutr 2006;84:18-28

96. Gómez-Alonso C, Naves-Diaz M, Fernández-Martin JL. Vitamin D status and secondary hyperparathyroidism: The importance of 25-hydroxyvitamin D cut-off levels. Kidney Int Suppl 2003;85:S44-S48

97. Dawson-Hughes B, Heaney RP, Holick MF, et al. Estimates of optimal vitamin D status. Osteoporos Int 2005;16:713-6

98. Heaney RP. The vitamin D requirement in health and disease. J Steroid Biochem Mol Biol 2005;97:13-19

99. Lips P, Duong T, Oleksik A, et al. A global study of vitamin D status and parathyroid function in postmenopausal women with osteoporosis: baseline data from the multiple outcomes of raloxifene evaluation clinical trial. J Clin Endocrinol Metab 2001;86:1212-21

100. Holick MF, Siris ES, Binkley N, et al. Prevalence of vitamin D inadequacy among postmenopausal North American women receiving osteoporosis therapy. J Clin Endocrinol Metab 2005;90:3215-24

101. Reginster JY. The high prevalence of inadequate serum vitamin D levels and implications for bone health. Curr Med Res Opin 2005;21:579-86

102. Rizzoli R, Eisman JA, Norquist J, et al. Risk factors for vitamin $\mathrm{D}$ inadequacy among women with osteoporosis: an international epidemiological study. Int J Clin Pract 2006;60:1013-19

103. Kiebzak GM, Moore NL, Margolis S, et al. Vitamin D status of patients admitted to a hospital rehabilitation unit: relationship to function and progress. Am J Phys Med Rehabil 2007; 86:435-45

104. Neuprez A, Bruyère $\mathrm{O}$, Collette J, et al. Vitamin D inadequacy in Belgian postmenopausal osteoporotic women. BMC Public Health 2007;7:64

105. Boonen S, Lips $P$, Bouillon $R$, et al. Need for additional calcium to reduce the risk of hip fracture with vitamin D supplementation: evidence from a comparative metaanlysis of randomized controlled trials. J Clin Endocrinol Metab 2007;92:1415-23

106. Rizzoli R, Boonen S, Brandi ML, et al. The role of calcium and vitamin D in the management of osteoporosis. Bone 2008; 42:246-9

107. Chapuy MC, Arlot ME, Duboeuf F, et al. Vitamin D3 and calcium to prevent hip fractures in the elderly women. N Engl J Med 1992;327:1637-42

108. Bischoff-Ferrari HA, Willett WC, Wong JB, et al. Fracture prevention with vitamin $\mathrm{D}$ supplementation: a meta-analysis of randomized controlled trials. JAMA 2005;293:2257-64

109. Jackson RD, LaCroix AZ, Gass M, et al.; Women's Health Initiative Investigators. Calcium plus vitamin D supplementation and the risk of fractures. N Engl J Med 2006;354:669-83

110. Tang BM, Eslick GD, Nowson C, et al. Use of calcium or calcium in combination with vitamin $\mathrm{D}$ supplementation to prevent fractures and bone loss in people aged 50 years and older: a meta-analysis. Lancet 2007;370:657-66

111. Avenell A, Gillespie WJ, Gillespie LD, et al. Vitamin D and vitamin $\mathrm{D}$ analogues for preventing fractures associated with involutional and post-menopausal osteoporosis. Cochrane Database Syst Rev 2009;2:CD000227

112. Bischoff-Ferrari HA, Dawson-Hughes B, Willett WC, et al. Effect of vitamin D on falls: a meta-analysis. JAMA 2004; 291:1999-2006

113. Sem SW, Sjøen RJ, Trygg K, et al. Vitamin D status of two groups of elderly in Oslo: living in old people's homes and living in own homes. Compr Gerontol [A] 1987;1:126-30

114. Kinyamu HK, Gallagher JC, Balhorn KE, et al. Serum vitamin $\mathrm{D}$ metabolites and calcium absorption in normal young and elderly free-living women and in women living in nursing homes. Am J Clin Nutr 1997;65:790-7
115. Lappe JM, Davies KM, Travers-Gustafson D, et al. Vitamin D status in a rural postmenopausal female population. J Am Coll Nutr 2006;25:395-402

116. Bolland MJ, Barber PA, Doughty RN, et al. Vascular events in healthy older women receiving calcium supplementation: randomised controlled trial. BMJ 2008;336:262-6

117. Segal E, Zinman C, Raz B, et al. Low patient compliance - a major negative factor in achieving vitamin $\mathrm{D}$ adequacy in elderly hip fracture patients supplemented with $800 \mathrm{IU}$ of vitamin D3 daily. Arch Gerontol Geriatr 2009 Jan 13 [Epub ahead of print]

118. Petrella RJ, Jones TJ. Do patients receive recommended treatment of osteoporosis following hip fracture in primary care? BMC Fam Pract 2006;7:31

119. Rossini M, Bianchi G, Di Munno O, et al.; Treatment of Osteoporosis in clinical Practice (TOP) Study Group. Determinants of adherence to osteoporosis treatment in clinical practice. Osteoporos Int 2006;17:914-21

120. Grant AM, Avenell A, Campbell MK, et al.; RECORD Trial Group. Oral vitamin D2 and calcium for secondary prevention of low-trauma fractures in elderly people (Randomised Evaluation of Calcium Or vitamin D, RECORD): a randomised placebo-controlled trial. Lancet 2005;365:1621-8

121. Ringe JD, van der Geest SA, Möller G. Importance of calcium co-medication in bisphosphonate therapy of osteoporosis: an approach to improving correct intake and drug adherence. Drugs Aging 2006;23:569-78

122. Ringe JD, Fardellone P, Kruse HP, et al. Value of a new fixedcombination pack of bisphosphonate, calcium and vitamin D in the therapy of osteoporosis: results of two quantitative patient research studies. Drugs Aging 2009;26:241-53

123. Boonen S, Laan RF, Barton IP, et al. Effect of osteoporosis treatments on the risk of non-vertebral fractures: review and meta-analysis of intention-to-treat studies. Osteoporos Int 2005;16:1291-8

124. Freedman KB, Kaplan FS, Bilker WB, et al. Treatment of osteoporosis: are physicians missing an opportunity? J Bone Joint Surg Am 2000;82A:1063-70

125. Gehlbach SH, Bigelow C, Heimisdottir M, et al. Recognition of vertebral fracture in a clinical setting. Osteoporos Int 2000; 11:577-82

126. Andrade SE, Majumdar SR, Chan KA, et al. Low frequency of treatment of osteoporosis among postmenopausal women following a fracture. Arch Intern Med 2003;163:2052-7

127. Elliot-Gibson V, Bogoch ER, Jamal SA, et al. Practice patterns in the diagnosis and treatment of osteoporosis after a fragility fracture: a systematic review. Osteoporos Int 2004;15:767-78

128. Perreault S, Dragomir A, Desgagné A, et al. Trends and determinants of antiresorptive drug use for osteoporosis among elderly women. Pharmacoepidemiol Drug Saf 2005;14:685-95

129. Roerholt C, Eiken P, Abrahamsen B. Initiation of antiosteoporotic therapy in patients with recent fractures: a nationwide analysis of prescription rates and persistence. Osteoporos Int 2009;20:299-307

130. Rabenda V, Vanoverloop J, Fabri V, et al. Low incidence of anti-osteoporosis treatment after hip fracture. J Bone Joint Surg Am 2008;90:2142-8

131. Gehlbach SH, Avrunin JS, Pulco E, et al. Fracture risk and antiresorptive medication use in older women in the USA. Osteoporos Int 2007; 18:805-10

132. Black DM, Steinbuch M, Palermo L, et al. An assessment tool for predicting fracture risk in postmenopausal women. Osteoporos Int 2001;12:519-28

133. Parikh S, Mogun H, Avorn J, et al. Osteoporosis medication use in nursing home patients with fractures in 1 US state. Arch Intern Med 2008;168:1111-15

134. Inderjeeth CA, Foo AC, Lai MM, et al. Efficacy and safety of pharmacological agents in managing osteoporosis in the old old: review of the evidence. Bone 2009;44:744-51

135. Boonen S, Dejaeger E, Vanderschueren D, et al. Osteoporosis and osteoporotic fracture occurrence and prevention in 
the elderly: a geriatric perspective. Best Pract Res Clin Endocrinol Metab 2008;22:765-85

136. Meunier PJ, Roux C, Seeman E, et al. The effects of strontium ranelate on the risk of vertebral fracture in women with postmenopausal osteoporosis. N Engl J Med 2004;350:459-68

137. Reginster JY, Seeman E, De Vernejoul MC, et al. Strontium ranelate reduces the risk of nonvertebral fractures in postmenopausal women with osteoporosis: treatment of peripheral osteoporosis (TROPOS) study. J Clin Endocrinol Metab 2005;90:2816-22

138. Ensrud KE, Black DM, Palermo L, et al. Treatment with alendronate prevents fractures in women at highest risk: results from the Fracture Intervention Trial. Arch Intern Med 1997;157:2617-24

139. Hochberg MC, Thompson DE, Black DM, et al.; the FIT Research Group. Effect of alendronate on the age-specific incidence of symptomatic osteoporotic fractures. J Bone Miner Res 2005;20:971-6

140. McClung MR, Geusens P, Miller PD, et al.; the Hip Intervention Program Study Group. Effect of risedronate on the risk of hip fracture in elderly women. N Engl J Med 2001;344:333-40

141. Harris ST, Watts NB, Genant HK, et al. Effects of risedronate treatment on vertebral and nonvertebral fractures in women with postmenopausal osteoporosis: a randomized controlled trial. Vertebral Efficacy with Risedronate Therapy (VERT) Study Group. JAMA 1999;282:1344-52

142. Reginster J, Minne HW, Sorensen OH, et al. Randomized trial of the effects of risedronate on vertebral fractures in women with established postmenopausal osteoporosis. Vertebral Efficacy with Risedronate Therapy (VERT) Study Group. Osteoporos Int 2000; 11:83-91

143. Boonen S, McClung MR, Eastell R, et al. Safety and efficacy of risedronate in reducing fracture risk in osteoporotic women aged 80 and older: implications for the use of antiresorptive agents in the old and oldest old. J Am Geriatr Soc 2004;52:1832-9

144. McCloskey EV, Beneton M, Charlesworth D, et al. Clodronate reduces the incidence of fractures in community-dwelling elderly women unselected for osteoporosis: results of a double-blind, placebo-controlled randomized study. J Bone Miner Res 2007;22:135-41

145. Lyles KW, Colón-Emeric CS, Magaziner JS, et al.; HORIZON Recurrent Fracture Trial. Zoledronic acid and clinical fractures and mortality after hip fracture. N Engl J Med 2007;357:1799-809

146. Neer RM, Arnaud CD, Zanchetta JR, et al. Effect of parathyroid hormone (1-34) on fractures and bone mineral density in postmenopausal women with osteoporosis. N Engl J Med 2001;344:1434-41

147. Boonen S, Marin F, Mellstrom D, et al. Safety and efficacy of teriparatide in elderly women with established osteoporosis: bone anabolic therapy from a geriatric perspective. J Am Geriatr Soc 2006; $54: 782-9$

148. Cramer JA, Amonkar MM, Hebborn A, et al. Compliance with bisphosphonate dosing regimens among women with postmenopausal osteoporosis. Curr Med Res Opin 2005;21:1453-60
149. Solomon DH, Avorn J, Katz JN, et al. Compliance with osteoporosis medications. Arch Intern Med 2005;165:2414-19

150. Blouin J, Dragomir A, Ste-Marie LG, et al. Discontinuation of antiresorptive therapies: a comparison between 1998-2001 and 2002-2004 among osteoporotic women. J Clin Endocrinol Metab 2007;92:887-94

151. Penning-van Beest FJ, Erkens JA, Olson M, et al. Determinants of non-compliance with bisphosphonates in women with postmenopausal osteoporosis. Curr Med Res Opin 2008; 24:1337-44

152. Weycker D, Macarios D, Edelsberg J, et al. Compliance with drug therapy for postmenopausal osteoporosis. Osteoporos Int 2006; 17:1645-52

153. Jones TJ, Petrella RJ, Crilly R. Determinants of persistence with weekly bisphosphonates in patients with osteoporosis. J Rheumatol 2008;35:1865-73

154. Siris ES, Harris ST, Rosen CJ, et al. Adherence to bisphosphonate therapy and fracture rates in osteoporotic women: relationship to vertebral and nonvertebral fractures from 2 US claims databases. Mayo Clin Proc 2006;81:1013-22

155. Blouin J, Dragomir A, Moride Y, et al. Impact of noncompliance with alendronate and risedronate on the incidence of nonvertebral osteoporotic fractures in elderly women. Br J Clin Pharmacol 2008;66:117-27

156. Penning-van Beest FJ, Erkens JA, Olson M, et al. Loss of treatment benefit due to low compliance with bisphosphonate therapy. Osteoporos Int 2008;19:511-17

157. Rabenda V, Mertens R, Fabri V, et al. Adherence to bisphosphonates therapy and hip fracture risk in osteoporotic women. Osteoporos Int 2008;19:811-18

158. van Eijken $M$, Tsang S, Wensing $M$, et al. Interventions to improve medication compliance in older patients living in the community: a systematic review of the literature. Drugs Aging 2003;20:229-40

159. George J, Elliott RA, Stewart DC. A systematic review of interventions to improve medication taking in elderly patients prescribed multiple medications. Drugs Aging 2009;25:307-24

160. Papaioannou A, Kennedy CC, Dolovich L, et al. Patient adherence to osteoporosis medications: problems, consequences and management strategies. Drugs Aging 2007;24:37-55

161. Brankin E, Walker M, Lynch N, et al. The impact of dosing frequency on compliance and persistence with bisphosphonates among postmenopausal women in the UK: evidence from three databases. Curr Med Res Opin 2006;22:1249-56

162. Reginster JY, Malaise $O$, Neuprez A, et al. Intermittent bisphosphonate therapy in postmenopausal osteoporosis: progress to date. Drugs Aging 2007;24:351-9

163. Boonen S, Vanderschueren D, Venken K, et al. Recent developments in the management of postmenopausal osteoporosis with bisphosphonates: enhanced efficacy by enhanced compliance. J Intern Med 2008;264:315-32

164. Sunyecz J. Optimizing dosing frequencies for bisphosphonates in the management of postmenopausal osteoporosis: patient considerations. Clin Interv Aging 2008;3:611-27

165. Black DM, Delmas PD, Eastell R, et al.; HORIZON Pivotal Fracture Trial. Once-yearly zoledronic acid fro treatment of postmenopausal osteoporosis. N Engl J Med 2007;356: 1809-22

\author{
CrossRef links are available in the online published version of this paper: \\ http://www.cmrojournal.com \\ Article CMRO-5154_4, Accepted for publication: 9 July 2009 \\ Published Online: 3 August 2009 \\ doi:10.1185/03007990903169262
}

